\title{
Formação docente e o Estágio Curricular Supervisionado: desafios e possibilidades em tempos de pandemia
}

\section{Teacher education and supervised internship: challenges and possibilities in times of remote teaching}

\author{
Vinicius Christian Pinho Correia ${ }^{1 *}$, Ermita do Amaral Rocha ${ }^{1}$, Leonardo Araújo Suzart ${ }^{1}$, \\ Fernanda Pereira Magalhães, ${ }^{1}$ Daniela Carvalho de Leal ${ }^{1}$, Lucas Gabriel Gonçalves ${ }^{1}$, Nielson \\ Barbosa dos Santos ${ }^{1}$, Américo Junior Nunes da Silva ${ }^{1}$
}

\begin{abstract}
RESUMO
Este artigo, resultado de uma experiência de estágio ocorrida em uma escola privada de um município do norte do Estado da Bahia, durante a pandemia, tem por objetivo refletir sobre as práticas pedagógicas desenvolvidas durante o Estágio Curricular Supervisionado, visando ampliar o olhar acerca do desenvolvimento da identidade docente e profissional, além disso, percebendo, práticas potencialmente lúdicas e metodologias ativas e alternativas que contribuem para os movimentos de ensino e aprendizagem da Matemática. Para isso, portanto, propõe-se a vivência de uma Gincana Matemática para turmas de $8^{\circ}$ e $9^{\circ}$ ano do Ensino Fundamental. Esta gincana teve como eixo metodológico a metodologia ativa, por meio da Gamificação. A gincana nos permitiu aproximação da realidade, trazendo-nos a articulação da teoria e prática, nos permitindo experiências e como consequência o desenvolvimento de nossas identidades docentes. Junto a isso, a aplicação da Gamificação nos mostrou ser uma possibilidade para o ensino com ferramentas pedagógicas potencialmente lúdicas. Desta maneira, as vivências a partir do Estágio permitiram refletir sobre as práticas pedagógicas e da docência, percebendo a relevância para a formação de educadores matemáticos mais qualificados e para a aprendizagem matemática dos estudantes.
\end{abstract}

Palavras-chave: Estágio Curricular Supervisionado; Educação Matemática; Metodologia Ativa; Metodologia Alternativa; Educação Básica.

\begin{abstract}
This article, the result of an internship experience that took place in a private school in a municipality in the north of the State of Bahia, during the pandemic, aims to reflect on the pedagogical practices developed during the Supervised Curricular Internship, in order to broaden the perspective on the development of the teaching and professional identity, in addition, realizing potentially playful practices and active and alternative methodologies that contribute to the teaching and learning movements of Mathematics. For this, therefore, it is proposed the experience of a Mathematical Gymkhana for classes of 8th and 9th grade of elementary school. This scavenger hunt had as its methodological axis the active methodology, through Gamification. The competition allowed us to approach reality, bringing us the articulation of theory and practice, allowing us experiences and, as a consequence, the development of our teaching identities. Along with this, the application of Gamification showed us to be a possibility for teaching with potentially playful pedagogical tools. In this way, the experiences from the Internship
\end{abstract}

1 Universidade do Estado da Bahia, Departamento de Educação, Campus VII. *E-mail: christianvinicius763@gmail.com 
allowed reflecting on the pedagogical practices and teaching, realizing the relevance for the formation of more qualified mathematics educators and for the mathematical learning of students.

Keywords: Supervised Internship; Mathematics Education; Active Methodology; Alternative Methodology; Basic education.

\section{INTRODUÇÃO}

O Estágio Curricular Supervisionado (ECS) é um componente obrigatório nos cursos de graduação, sendo um espaço de formação importante para os futuros profissionais, no qual, por muitas vezes, é o primeiro momento de vivências e experiências na área de atuação para a qual está se qualificando. O ECS está previsto, para a Universidade do Estado da Bahia (UNEB), na Resolução CONSEPE n 2016/2019.

Como assevera Pimenta (1999), o estágio é um momento de construção da identidade profissional, onde se possibilita momentos críticos e reflexivos das práticas docentes. Sendo assim, nele temos a oportunidade de vivenciar e de nos aproximar da realidade escolar, do "chão da sala de aula", e daí, refletirmos e desenvolvermos práticas, muitas delas oriundas de pesquisa, para entender melhor o ambiente de ensino e aprendizagem, no nosso caso da Matemática.

Dessa forma, o ECS está presente como componente de oferta obrigatória no Curso de Licenciatura em Matemática da Universidade do Estado da Bahia - UNEB, Campus VII, em Senhor do Bonfim. Sendo assim, são ofertado 405 horas de estágio, dividida em quatro componentes curriculares nos últimos quatro períodos do curso: ECS I (75h), voltado à observação nos anos finais do Ensino Fundamental; o ECS II (90h), para docência nos anos finais do Ensino Fundamental; o ECS III (120h), que consiste na construção e vivência de projetos de intervenção pedagógica para o ensino de Matemática; e por último o ECS IV (120h), que se destina a docência no Ensino Médio.

O ECS III, normalmente é oferecido aos licenciandos no $7^{\circ}$ semestre. No entanto, por conta da pandemia da Covid-19, algumas atividades presenciais foram suspensas. Com isso, visando assegurar a vida, foi orientado quanto a necessidade do distanciamento social afim de diminuir a disseminação do contágio e o número de mortes. Destarte, foi necessário repensar a sua oferta para o $6^{\circ}$ semestre, para que fosse 
possível ter campo de estágio para todos os estagiários, uma vez que muitas escolas estavam sem desenvolver atividades síncronas, desenvolvendo as suas atividades remotas a partir do envio de atividades.

Este componente, o ECS III, organiza-se em dois momentos: uma parte destinase a observação das aulas de um $8^{\circ}$ ano do Ensino Fundamental, percebendo as dinâmicas de trabalho possibilitadas pelo professor supervisor, que é o docente da escola que nos recebe para realizar as atividades, permitindo que nos aproximemos da realidade educacional e da rotina da escola e da sua turma, algo que nos permite construir um diagnóstico que ajudará no planejamento da intervenção; e em um segundo momento, vivenciar o projeto construído para aquela determinada realidade.

Nesse ínterim, é preciso levar em consideração que estamos vivendo um momento crítico, em virtude da pandemia da Covid-19, e que as aulas anteriormente presenciais hoje acontecem de maneira remota; algo que nos leva a (re)pensar estratégias para serem desenvolvidas com os alunos e que aprimorem o processo de ensino e aprendizagem da Matemática, tudo respeitando o distanciamento social estabelecido pelas entidades de saúde.

Com o olhar para esse processo, agora virtual, assegurando que seja de forma divertida e fazendo com que o aluno deixe de ser apenas um "receptor" de informações [como acontece em muitos espaços escolares] e passe a ser o principal responsável na construção do seu conhecimento, que pensamos sobre a realização de uma oficina que, através do senso de coletividade e do trabalho em equipe desperte o interesse dos estudantes em aprender a Matemática. Dessa forma, optamos pela elaboração e execução de uma Gincana Matemática, em um movimento de construção de atividades gamificadas.

A construção da proposta de intervenção pedagógica, uma oficina, teve como intuito dinamizar o espaço da sala de aula virtual do $8^{\circ}$ ano com a prática de atividades potencialmente lúdicas, apropriando-se de diferentes metodologias e recursos didáticos digitais para ensinar os conteúdos de Matemática. Nessa perspectiva, portanto, salientamos que o objetivo deste artigo é refletir sobre as práticas pedagógicas desenvolvidas durante o ECS III, visando ampliar o olhar acerca do desenvolvimento da identidade docente e professional; além disso, refletindo criticamente sobre práticas potencialmente lúdicas e metodologias ativas e alternativas que podem contribuir para os movimentos de ensino e aprendizagem da Matemática. 


\title{
CONSIDERAÇÕES INICIAIS SOBRE O ESTÁGIO CURRICULAR SUPERVISIONADO
}

O estágio supervisionado é um importante espaço de formação e desenvolvimento profissional, como bem asseveram Suzart e Silva (2020) e Correia e Silva (2020). Assim sendo, partindo do que revelaram os autores anteriormente referenciados, cabe-nos conjecturar que o estágio exerce importante função para a formação de futuros professores, visto que proporciona momentos de vivência e reflexão crítica da docência. De acordo com Pimenta (2004)

\begin{abstract}
O estágio sempre foi identificado como parte prática dos cursos de formação de profissionais, em contraposição à teoria. Não é raro ouvir, a respeito dos alunos que concluem seus cursos, referências como "teóricos", que a profissão se aprende "na prática", que certos professores e disciplinas são por demais "teóricos". Que "na prática a teoria é outra". No cerne dessa afirmação popular, está a constatação, no caso da formação de professores, de que o curso nem fundamenta teoricamente a atuação do futuro profissional nem toma prática como referência para fundamentação teórica. Ou seja, carece de teoria e de prática. (PIMENTA, 2004, p. 33)
\end{abstract}

Desta forma, partindo do que revelou Pimenta (2004) anteriormente, percebemos que o estágio, muitas vezes, é erroneamente entendido como um momento dedicado à prática, como um polo prático do curso. Afirmações como essa apontam certa fragilidade de alguns cursos de formação inicial de professors: a dicotomização teoria e prática; algo que Silva (2020) discutiu como descaracterizador, muitas vezes, da natureza dos cursos de formação de professores e a sua relação com o "chão da escola". Mas afinal, qual a importância dos estágios supervisionados em cursos de licenciatura? para responder essa questão, precisamos antes entender qual a finalidade do estágio, o seu objetivo. Para ampliar o olhar acerca do que perguntamos anteriormente, Pimenta (2012) revela que é

[...] proporcionar que o aluno tenha uma aproximação à realidade na qual irá atuar. Portanto, não deve colocar o estágio como o polo prático do curso, mas como uma aproximação à prática, na medida em que será consequente à teoria estudada no curso, que, por sua vez, deverá se constituir numa reflexão sobre e a partir da realidade da escola [...] (PIMENTA, 2012, p. 81) 
Entendemos, partindo do que nos apresentou Pimenta (2012), que o estágio é fundamentalmente um momento da formação do futuro professor em que há um entrelace de teoria e prática, de maneira pendular, como asseveraram Suzart e Silva (2020); ou seja, que, não só, a prática seja substancialmente sustentada por uma teoria, mas que também essa teoria condicione a uma reflexão a partir das vivências, ressignificando esta mesma teoria, agora para aquela dada realidade. Na mão do que evidenciamos anteriormente, Freitas, Costa e Lima (2017, p. 37-38) também nos afirmam que "o estágio não pode ser tratado como a 'hora da prática', e sim como o momento em que os futuros professores buscam entender o que é ser professor e quais os diferentes determinantes que interferem na construção de sua identidade docente".

Destarte, a partir do momento em que o estagiário se encontra em uma sala de aula, vivenciando situações que são particulares da sua futura profissão, articulando a prática e teoria, de maneira que visualize, vivencie e aprofunde o que estudou ao longo de seu curso de formação, acaba por se constituindo enquanto docente. Nessa direção, cabe considerar a vivência de observação em sala de aula como algo também significativo e importante nesse processo.

\section{ESTÁGIO SUPERVISIONADO: DESAFIOS DE UM CONTEXTO PANDÊMICO}

Para muitos, o estágio ainda continua sendo o primeiro contato com a docência, enquanto futuro professor; com isso, é comum ficar nervoso e apreensivo, muitas vezes com receio dos alunos não gostarem dos métodos utilizados durante suas aulas ou que não aprendam, como planejado. As aulas presenciais, por causa da pandemia, foram suspensas; tudo isso para evitar expor os estudantes ao vírus. Neste sentido, para que a educação não parasse e os estudantes não ficassem sem estudar, algumas instituições aderiram ao ensino remoto. De acordo com Souza e Ferreira (2020), estados e municípios tomaram medidas solidárias e necessárias para evitar a disseminação do vírus, suspendendo as aulas em março de 2020, orientados pela portaria $n^{\circ} 343 / \mathrm{MEC}$, que determinou, também, a substituição das aulas presenciais por aulas remotas, mediadas por tecnologias digitais.

Pensando no quanto o Estágio Curricular Supervisionado é importante para formação de docentes preparados para atuarem na educação do país, como 
evidenciamos anteriormente, cabe aqui discutir aspectos relacionados aos desafios e possibilidades em tempos de ensino remoto. A respeito diversas práticas vivenciadas nesse período, Saraiva, Traversini e Lockmann (2020) salientam que

\begin{abstract}
A docência nos tempos de pandemia é uma docência exausta, ansiosa e preocupada. Que quer acertar, mas que avança no meio da incerteza e da adversidade - e que não tem a menor ideia do caminho. Como todos, os professores estão imersos em uma névoa e seguem através dela, buscando fazer o melhor, mas sem garantias. (SARAIVA, TRAVERSINI e LOCKMANN, 2020, p. 17)
\end{abstract}

Ainda segundo as autoras anteriormente referenciadas e por Silva (2021), essas dificuldades se dão, também, por falta de formação para manusear as novas ferramentas utilizadas nas aulas, pois durante a formação de muitos houve ausência do trabalho com tecnologias, trazendo essas consequências nesse período. Os desafios são imensos, pois acarretam sentimentos de apreensão sobre o conseguir trabalhar com os alunos de forma produtiva, em que se consigam significativas aprendizagens. Segundo Saraiva, Traversini e Lockmann (2020, p. 18) a pandemia "tende a fortalecer a intensificação e a autointensificação do trabalho, aumentando a exaustão docente. Há um difícil equilíbrio entre continuar as atividades letivas e administrar o momento atual que tem gerado estresse e ansiedade".

Neste sentido, na mão do que evidenciamos anteriormente, Silva (2021) destaca que

[...] O contexto pandêmico nos (im)pôs uma nova realidade e uma, ainda que temporária, nova estrutura e realidade escolar, o que exige uma prática que muitos não conheciam até aqui. Até os professores mais experientes precisam reaprender a como ser docentes nessa situação de distanciamento social. Os professores iniciantes são, desse modo, levados a desenvolver a docência em um processo em que todos precisamos (re)aprender a ser docentes. (SILVA, 2021, p. 72)

De fato, percebemos que esse momento de pandemia nos trouxe a necessidade de perceber, na prática, a formação como um continuum, pois no desenvolver das atividades docentes surgem imprevistos e desafios aos quais precisamos nos atentar, sobretudo por serem questões que implicam diretamente para o nosso fazer pedagógico (SILVA, 2018). Neste sentido, o ECS III e a sua proposta de observação de aulas, construção e vivência de um projeto de intervenção, nos trouxe algumas dificuldades 
em relação aos manusear das ferramentas digitais; mas por outro lado, por conta da nossa imersão e estudo sobre, nos prepararam para sua utilização no futuro.

Como ressaltou Silva (2021), ninguém pode prever uma pandemia, mas por ter ocorrido em nosso momento de formação inicial, mesmo sendo um momento difícil enfrentado por todos, deixou marcar e, de certa forma, influenciará para a nossa [futura] prática docente, nos preparando e alertando para possíveis imprevistos [que podem ocorrer] e quanto à necessidade de direcionarmos o olhar acerca das diversas ferramentas tecnologias que podem ser utilizadas nas aulas.

\section{RESSIGNIFICANDO O ENSINO DE MATEMÁTICA A PARTIR DE METODOLOGIAS ATIVAS E ALTERNATIVAS}

O ensino de Matemática ainda é abordado, em muitas salas de aula, de forma "tradicional”, utilizando-se principalmente da exposição de conteúdos, onde os alunos replicam resoluções de exercício em seus cadernos. Foi assim para muitos de nós, autores, quando estudantes da Educação Básica, e assim temos percebido, infelizmente, em momentos de aproximação com a escola, seja nos momentos de estágio ou em outros espaços de formação promovidos pela universidade. Essa realidade, que apresentamos anteriormente, não está sendo diferente no ensino remoto [considerando as nossas observações]; temos percebido que muitos professores, sem formação apropriada, sentem-se despreparados para usarem das tecnologias digitais e metodologias ativas e alternativas para a promoção de aprendizagens matemáticas. Nessa direção, o Documento Curricular Referencial da Bahia (2019), ressalta a importância de substituir formas tradicionais de ensino por metodologias de aprendizagem ativa, assim, colocando os alunos como protagonistas nos processos de ensino e aprendizagem, principalmente utilizando-se de recursos da vivência dos estudantes.

Com isso, a partir das observações realizadas durante o ECS III, propomos construir uma oficina pedagógica. De acordo com Paviani (2009, p. 78), “uma oficina é, pois, uma oportunidade de vivenciar situações concretas e significativas, baseada no tripé: sentir-pensar-agir”. Destarte, entendemos como importante no processo de ensinar e aprender, possibilitar aos alunos vivências que os motivem a participarem e interagirem, uns com os outros; além disso, metodologias como essa, podem possibilitar que os alunos se tornem protagonistas na construção de seu conhecimento. Nesse 
sentido, entendemos que as metodologias ativas podem ser um caminho interessante na busca desse protagonismo. Segundo Morán (2015, p. 17)

\begin{abstract}
A maior parte do tempo - na educação presencial e a distância ensinamos com materiais e comunicações escritos, orais e audiovisuais, previamente selecionados ou elaborados. São extremamente importantes, mas a melhor forma de aprender é combinando equilibradamente atividades, desafios e informação contextualizada. Para aprender a dirigir um carro, não basta ler muito sobre esse tema; tem que experimentar, rodar com o ele em diversas situações com supervisão, para depois poder assumir o comando do veículo sem riscos.
\end{abstract}

Assim, Morán (2015) descreve a metodologia ativa com ponto inicial no processo de reflexões, desenvolvimento cognitivo, da generalização e no repensar de novas práticas; além disso, “[...] o aprendizado se dá a partir de problemas e situações reais" (MORÁN, 2015, p. 19). Dessa forma, reconhecemos este como caminho interessante de se trabalhar com a educação básica, pois possibilita aos alunos perceberse responsável, também, pela constituição do seu conhecimento matemático.

Além das metodologias ativas, temos as metodologias alternativas que são possibilidades de diversificar o ambiente da sala de aula. D'Ambrosio (1989) discutia a necessidade de adaptar o ensino de matemática para uma nova realidade, para que o ensino 'tradicional' que é, para ela, “a típica aula de matemática em nível de primeiro, segundo ou terceiro graus ainda é uma aula expositiva, em que o professor passa para o quadro negro aquilo que ele julga importante.” (D’AMBROSIO, 1989, p. 1), desse espaço para outras metodologias como as fundamentadas na Resolução de Problemas, Modelagem, Etnomatemática, História da matemática, o uso de computadores e, também, d Jogos Matemáticos.

Nesse ínterim, as metodologias alternativas são possibilidades no ensino e aprendizagem matemática, pois auxiliam na construção do matematizar dos estudantes dentro da sala de aula. De acordo com Barbosa e Alves (2019, p. 50) as metodologias alternativas têm como intuito principal auxiliar os docentes em sua prática pedagógica, possibilitando que aperfeiçoem suas aulas, que saiam da dicotomia de aulas puramente expositivas para aulas interativas onde alunos e professor podem trabalhar lado a lado na construção de uma aprendizagem com significado.

Neste contexto, percebemos como importante nas vivências da sala de aula a utilização da metodologia ativa da Gamificação, pois se articula ao foco dado para o 
desenvolvimento da Gincana de Matemática, por nós proposta. Sendo assim, Alves, Minho e Diniz (2014, p. 83) afirmam que "a gamificação surge como uma possibilidade de conectar a escola ao universo dos jovens com o foco na aprendizagem, por meio de práticas como sistemas de ranqueamento e fornecimento de recompensas". Nesse sentido, trabalhar as aulas gamificadas, pode possibilitar a utilização das mecânicas de jogos, acabando experienciando algo potencialmente lúdico.

Nesse movimento, portanto, percebemos que o entendimento de Gamificação e o seu surgimento se alinha com outras áreas, diferentes da Educação. Isso, de certa forma e em nossa leitura, cria um ambiente de disputa exacerbada, que muitas vezes impossibilita a criação de ambientes ludicamente inspirados e, consequentemente, num movimento saudável de relações interpessoais e, consequentemente, de matematizar. Entendemos que para vivenciar algo dessa natureza nos exigiria um movimento de ressignificação, adaptando a Gamificação para ambientes escolares. Para isso, portanto, precisamos retirar das práticas gamificadas o caráter neoliberal e de controle das vivências lúdicas. Esperamos que ao abordar dos conteúdos matemáticos por meio de atividades potencialmente lúdicas, as quais consigam se articular com as metodologias citadas anteriormente, podem facilitar nesse processo da construção do pensamento matemático e dos movimentos de matematizar. Essas atividades, se e quando bem conduzidas, podem levar os alunos a construírem os significados dos conceitos matemáticos apresentados em sala de aula, extrapolando a percepção utilitarista do uso de fórmulas prontas e sem significação, favorecendo a liberdade e criatividade.

Portanto, entendemos por ludicidade, nesse momento e para esse texto e vivência em particular, como "um estado interno, que pode advir das mais simples às mais complexas atividades e experiências humanas" (LUCKESI, 2014, p.18). Sendo assim, não podemos definir algo como lúdico, pois somente o indivíduo participante poderá sentir esse sentimento, pois é individual. Jogos e brincadeiras são ferramentas que levam a Matemática até o aluno de uma forma divertida e prazerosa, pois eles aprendem brincando; porém, por si só não podem ser encaradas como atividades lúdicas, mas sim possuem grande potencial a ser lúdico para os sujeitos que estão participando, até porque "ela [a ludicidade] não é igual para todos" (LUCKESI, 2014, p.18).

AS OBSERVAÇÕES EM "SALA DE AULA" REMOTAMENTE: BREVE DESCRIÇÃO DA ESCOLA, TURMA E DO PROFESSOR SUPERVISOR 
O Estágio Curricular Supervisionado III aconteceu em uma escola particular de um município da região norte do Estado da Bahia. Para que conhecêssemos a instituição, do ponto de vista político pedagógico, fizemos a leitura do Projeto Político Pedagógico (PPP). No PPP encontramos que o seu objetivo geral é o de promover uma “educação integral de qualidade que desenvolva a consciência e o senso crítico de modo a contribuir com a formação da personalidade dos alunos". Isso mostra que, para além de ensinar, a escola possui um papel fundamental para a formação de sujeitos críticos e reflexivos, que ocupem um lugar significativo na sociedade.

Antes que pudéssemos acompanhar as aulas do professor supervisor, houve um encontro na plataforma Meet com ele a coordenadora pedagógica, para que nos orientassem sobre as normas da escola, as dinâmicas estabelecidas nesse momento de pandemia e as rotinas da escola. Tudo isso era importante para que pudéssemos planejar nossas observações e, futuramente, a intervenção.

Como destacado no início deste texto, foi possível no momento de observação conhecer melhor o professor e, também, a turma, entendendo as dinâmicas construídas por eles e como se davam os movimentos de ensinar e aprender Matemática. O observar foi um momento importante nesse percurso, sobretudo para a construção da nossa proposta de oficina, pois a partir dela percebemos, durante as aulas de Matemática, algumas dificuldades frequentes com o tratar alguns conceitos em sala de aula virtual.

Durante o período das observações na sala de aula virtual, propusemos ao professor supervisor um questionário, construído pelo professor orientador, validado por toda a turma de estágio. O questionário continha várias perguntas e objetivava conhecer melhor o professor, o que pensava a Matemática e seu ensino, bem como entender como estava sendo aquele momento de pandemia para ele. Mostraremos, a seguir, alguns dos dados obtidos a partir da aplicação do questionário.

O professor supervisor é graduado em licenciatura em Matemática e tem 6 anos de experiência profissional. Atualmente tem carga horária de 20 horas semanais em instituição privada e é professor nas disciplinas de Matemática e Física. Em uma de suas respostas, o professor supervisor cita que escolheu o curso de Licenciatura em Matemática por sempre se identificar com números. O mesmo revela que aprendeu a gostar da docência ao entrar no curso. Ainda segundo ele, considera que a "troca de aprendizagem constante leva a ser um bom professor de matemática" e que o curso de 
licenciatura o ajudou a ser esse bom professor, levando-o a entender que existem várias maneiras de pensar e que uma das alegrias que ele tem em ser professor é formar pessoas conscientes. Quando perguntado sobre as angústias de ser professor ele afirma que uma delas é "não conseguir passar o aprendizado aos alunos". Ele atribui nota 7, de 0 a 10, de satisfação com a sua profissão e comenta que acredita que precisa evoluir como educador.

Quanto aos desafios do contexto pandêmico, ele afirma se sentir preparado para as demandas do contexto pandêmico, apesar de sentir angústia diante da adaptação à nova realidade escolar. Ao ser questionado se recebeu formação para o trabalho na pandemia, afirma que não, e completa que o curso de licenciatura também não o preparou para o uso de diferentes tecnologias digitais. Quando perguntado se os estudantes estão conseguindo aprender os conteúdos nesse período ele afirma que sim, e complementa que isso acontece "devido às diversas formas disponíveis aos alunos para complementar o ensino". Para ele o papel da escola, nesse período pandêmico, é fundamental, e que "pais, alunos, professores e grupo de gestão precisam andar juntos".

Durante quatro semanas, portanto, realizamos as observações da turma. Em nossas observações percebemos que alguns estudantes tinham dificuldade em compreender os conceitos matemáticos dos conteúdos abordados pelo professor supervisor; com isso, passamos a discutir e refletir sobre essas dificuldades, em encontros realizados entre os estagiários, tentando levantar possibilidades do que poderia ser feito para que essas dificuldades fossem sanadas. Foram esses movimentos reflexivos que pautaram a construção de nossa oficina.

Com as nossas observações, percebemos que as aulas ministradas possuíam certo padrão, sendo definidas por momentos de recepção dos alunos na plataforma Meet; em seguida havia a realização da chamada, e por fim a utilização do programa Word, seja para a explicação de um novo conteúdo ou correção de atividades. Em sua maioria, as aulas observadas utilizaram-se do Word e, em um momento, manuseou-se outra ferramenta diferente, como o software Geogebra, por exemplo.

A turma, de um modo geral, era pouca participativa durante as aulas, onde somente um dos alunos permanecia o decorrer da aula com a câmera aberta e outros somente abriam o áudio quando havia alguma dúvida, e alguns faziam a utilização do chat; fazendo com que, diversas vezes durante as aulas, o professor cobrasse a participação dos alunos. 


\section{O PLANEJAMENTO DA OFICINA}

Durante o processo de observação, como revelamos na seção anterior, refletimos sobre estratégias que contribuíssem para a aprendizagem matemática daquele referido público. Nesse percurso, foram realizadas diversas reuniões virtuais entre os estagiários para que organizássemos as atividades de forma significativa e divertida para os alunos, não perdendo de foco a aprendizagem da matemática e a valorização da criatividade nos processos de matematizar. Foi durante esses encontros virtuais, onde se discutia a proposta de intervenção, que selecionamos os dispositivos metodológicos, validamos a sequência da proposta, para sua posterior vivência.

Destarte, pensamos para a oficina a realização de uma Gincana Matemática, pois entender que ela possibilitaria que os estudantes desenvolvessem diversificadas atividades, nas quais, sempre estarão na posição de participantes ativos na construção das tarefas; sendo que, a cada atividade concluída, somaríamos pontos para ranquear as equipes participantes. Neste sentido, buscamos envolver os conteúdos que foram trabalhados nas aulas observadas para que os alunos melhor os entendessem e vivenciassem este mesmo aprendizado em outra perspectiva, a partir das atividades potencialmente lúdicas propostas.

Assim, destacamos como conteúdos que serão desenvolvidos na Gincana de Matemática: i) as operações aritméticas; ii) noções de geometria; iii) potenciação e radiciação. Reconhecemos que o estudo desses assuntos é de extrema importância para os alunos, pois lhes possibilitam desenvolver sua criatividade, bem como, fazer relações com o seu dia a dia.

As quatro operações fundamentais são: subtração, adição, multiplicação e divisão. São trabalhadas durante toda a Educação Básica e o domínio de resoluções com as quatro operações é fundamental e constitui-se como conhecimento prévio para a aprendizagem de outros objetos de conhecimento, como os envoltos as unidades temáticas de Geometria, Grandezas e Medidas, Probabilidade e Estatística, Álgebra e Números.

A respeito do ensino da Geometria, Iezzi et al. (2004, p. 272) ressaltam a importância dessa área da Matemática pois auxilia "na compreensão do mundo real em que vivemos, bem como na ampliação de nossos conhecimentos em Matemática”. Além 
disso, enfatizam que devemos iniciar os estudos a partir de situações e materiais concretos, aprendendo a visualizar o espaço geométrico. Logo, percebemos que o estudo da Geometria é de total importância, pois permite a compreensão do nosso dia a dia.

Neste sentido, destacamos também a Potenciação e Radiciação que, como foi dito, foram conteúdos ensinados nas aulas e que decidimos por também trabalhá-los durante as oficinas para sanar, caso exista, dúvidas dos participantes. Giovanni (1999) destaca que a potenciação é muito utilizada em diversos campos de conhecimentos humanos, no que diz respeito à simplificação de um módulo grande ou pequeno. Name (2005) define a potenciação como sendo uma multiplicação de fatores iguais. Percebemos então que a potenciação expressa um número na forma de potência e este é multiplicado várias vezes, como por exemplo, $\mathbf{a}^{\mathbf{n}}$, onde $\mathbf{n}$ é o número de fatores e a é o fator que repete em decorrência a n. Por outro lado, a radiciação calcula o número que quando elevado a um determinado expoente, produz um valor chamado raiz, resultado inverso da potenciação.

Foram esses conteúdos elencados para serem trabalhados durante a oficina, em que antes foi escrito um projeto de intervenção, o qual se referia a Gincana. O mesmo foi aprovado pelo professor orientador, pelo professor supervisor e depois pela coordenadora pedagógica da escola. A partir desse retorno, foi revisto alguns detalhes e iniciamos a Gincana.

\section{VIVENCIANDO A GINCANA MATEMÁTICA}

Após a Gincana ser planejada, aprovada e validada, iniciamos os preparativos para a sua execução. Seguindo o formato do colégio, utilizamos a plataforma Google Meet para podermos vivenciar os momentos de aprendizagem com os alunos. A oficina aconteceu em quatro semanas e a cada semana tivemos três encontros, nos dias de segunda, quarta e sexta. Os encontros ocorriam de forma síncrona através da plataforma do Google Meet, onde enviávamos o link às 14:20h e iniciando as atividade às 14:30h como planejado, e compartilhávamos esse link de acesso a sala por meio de um grupo do WhatsApp criado para conversar, tirar dúvidas, enviar as tarefas da gincana e manter o maior contanto com os participantes da oficina. Além disso, construímos um perfil do Instagram para cada equipe participante da Gincana, para darmos visibilidade a todas as 
atividades desenvolvidas nesse processo de oficina. A seguir, apresentaremos o que aconteceu durante as semanas.

\section{Apresentação da oficina pedagógica}

Nesse primeiro encontro nos apresentamos e pedimos para que os estudantes, também, se apresentassem. Além disso, apresentamos a nossa proposta de trabalho, incluindo os objetivos e as atividades que seriam desenvolvidas durante as quatro próximas semanas. Tivemos a presença de uma mãe, que ficou curiosa e queria saber como aconteceria à oficina, do professor supervisor e do professor orientador, além da coordenadora da Escola. Utilizamos slides e explicamos detalhadamente como aconteceria toda a oficina, perguntando sempre se eles tinham alguma dúvida. Alguns abriram o áudio e conversaram um pouco conosco. Todos os estagiários estavam presentes nesta tarde. Os estudantes se mostraram empolgados e curiosos para saber como aconteceriam às aulas.

\section{As quatro operações fundamentais e a resolução de problemas}

Preparamos para este segundo encontro uma revisão das quatro operações fundamentais, bem como, da resolução e construção de problemas matemáticos que envolvessem esse objeto de conhecimento. Assim, iniciamos nosso encontro falando das quatro operações fundamentais. Trouxemos a definição destas e logo após, compartilhamos um vídeo para compartilhar e discutir a partir de situações cotidianas.

$\mathrm{Na}$ sequência, abordamos a construção de problemas utilizando as quatro operações. Para isso utilizamos slides e definimos o que é um problema matemático. Feito isso, mostramos alguns passos que podem ser utilizados para a resolução, bem como também, da construção dos problemas para que os alunos pudessem perceber como se dava esse processo e mostramos que, além desses, a criatividade também pode ser utilizada para resolução de problemas desse tipo. Por fim, finalizamos nosso encontro solicitando que construíssemos cinco problemas matemáticos envolvendo as quatro operações fundamentais da matemática levando em consideração o que foi mostrado.

Resolução de problemas e jogo plano cartesiano interativo 
Nesse terceiro encontro, tivemos presentes as duas turmas participantes da oficina, tanto o $8^{\circ}$ como o $9^{\circ}$ ano. Iniciamos nossa atividade resolvendo os problemas matemáticos construídos por eles. Cada turma respondia uma pergunta construída pela equipe adversária, evidenciando o processo utilizado para chegaram ao resultado. A turma do $9^{\circ}$ ano acertou as cinco questões e a turma do $8^{\circ}$ ano acertou quatro questões, com isso o $9^{\circ}$ ano ganhou 100 pontos.

Dando continuidade ao que foi proposto para o dia, depois que a oficina da construção e resolução de problemas findou, iniciamos o jogo plano cartesiano interativo. Explicamos com detalhes como funcionaria; então pedimos para uma das equipes iniciarem, dando tempo para a equipe adversária responder. Foi assim até ser aberto o terceiro quadrado, quando através de discussões entre os Estagiários do oitavo e nono ano enquanto estava ocorrendo o jogo, resolvemos finalizar o que foi planejado para o dia por conta de já termos passado do tempo limite. Percebemos que os alunos demonstravam estar cansados. Por conta disso, resolvemos replanejar e dar continuidade em outro momento.

O cansaço dos alunos foi notório; onde poucos interagiram nessa segunda atividade proposta. Entretanto, reavaliamos a forma como conduzimos esse encontro, e buscaremos estimular a participação e interação. Apesar do encontro não ter saído como planejamos, algo que acontece e que, como destacou Silva et al. (2014), faz parte dos movimento de planejamento, foi um momento de muita aprendizagem não só para os alunos, mas também para nós estagiários, pois percebemos que é importante garantir o avaliar das vivências propostas, entendendo o que funcionou ou não.

\section{Construindo o matematizar através das fotografias e musicalização}

Dessa forma, iniciamos o quarto encontro de acordo ao que tínhamos planejado e tudo ocorreu da maneira que esperávamos. Nesse encontro, tivemos uma faixa de seis a sete alunos da escola presente. Desta forma, buscamos trabalhar com a matemática do dia a dia dos alunos, bem como também com a paródia, sendo uma metodologia diferente para ser empregada a fim de desenvolver a criatividade e aprendizagem dos alunos.

Assim, dividimos esse encontro em dois momentos. No primeiro momento, trouxemos imagens do nosso cotidiano e objetos que nos deparamos no nosso dia a dia, buscando mostrar aos alunos a matemática presente nestes. À medida que íamos 
mostrando as imagens, perguntávamos aos alunos onde eles viam a matemática e obtivemos boas respostas e boas participações. A maioria dos alunos que ali estavam se envolveram, mostrando a matemática que percebiam naquelas referidas imagens. Esse movimento, como apresentado por Silva, Souza e Cruz (2020), permitiu que (re) significássemos algumas concepções sobre a Matemática, sobretudo que se trata de algo difícil e descontextualizado das diversas situações cotidianas.

Além disso, apresentamos nos slides duas charges/memes que demonstram aspectos matemáticos. A primeira charge era uma crítica à construção da matemática dentro da sala de aula, no qual o professor se negava a explicar a matemática cotidiana para os estudantes, exclamando ser uma "baboseira" o aluno querer saber onde iria utilizar a matemática no seu dia a dia. Já na segunda charge apresentada, dois personagens conversavam sobre não utilizar a matemática em seu dia a dia enquanto saíam da escola após a aula de matemática, no entanto no último quadrinho percebemos uma das personagens utilizando-a ao realizar um pedido de uma pizza. Destarte, propusemos a leitura de imagens no intuito de realizar uma reflexão sobre como a matemática está presente ao nosso redor, e, que os estudantes utilizam com frequência mesmo não reconhecendo/percebendo nas tarefas que realizam diariamente.

No segundo momento, fizemos um resgate de algumas músicas, juntamente com os alunos, que abordasse a matemática; assim, mostramos para eles paródias e o que ela é. Logo, trouxemos também alguns exemplos de paródias construídas com conteúdos matemáticos. Houve também uma boa participação dos alunos. Nesse sentido, foi perceptível que os estudantes conseguiram compreender elementos matemáticos apresentados nas paródias.

Assim, finalizamos o nosso encontro solicitando aos alunos duas atividades. A primeira foi que eles fotografassem cinco situações do dia a dia, onde visualizassem a Matemática e, a segunda, para que escolhessem um conteúdo e uma música de sua preferência e construíssem uma paródia. Essa atividade será avaliada por um convidado especial e contará como pontuação no ranking da gincana, além de ser publicada no Instagram da equipe.

\section{$O$ ato de repensar e replanejar: refletindo as nossas práticas}

Nesse encontro retomamos a atividade que não foi finalizada na primeira semana. Consoante o que aponta Silva et al (2014, p. 47) o ato "planejar vai muito além 
de preencher quadrinhos, como foi diagnosticado em algumas escolas onde aconteceu o estágio. É importante colocar o planejamento em prática, e que implica vivenciar e perceber os possíveis erros, e corrigi-los para atividades futuras". Nessa perspectiva, durante a realização da proposta para gincana, observamos falhas em sua execução, e que comprometeram o ato de aprender e ser potencialmente lúdico. Pois, visto que no encontro que iniciamos essa atividade, foi feita outra que excedeu o tempo que planejamos e, assim, deixando os estudantes exaustos para continuar nessa outra atividade. Além disso, as regras adotadas para tal jogo tiveram que ser revista para que fosse executado e ocorresse tudo bem, respeitando a perspectiva metodológica adotada.

Dessa forma, nesse encontro retomamos o jogo Plano Cartesiano Interativo, informando sobre as alterações realizadas. No decorrer da interação os quadrados foram sendo abertos, como mostra a figura a seguir, e os alunos iam comunicando as suas estratégias de resolução:

Imagem 01 - Recorte do Slide com o Material Didático intitulado "Plano Cartesiano Interativo", após algumas jogadas realizadas pelos participantes da Gincana

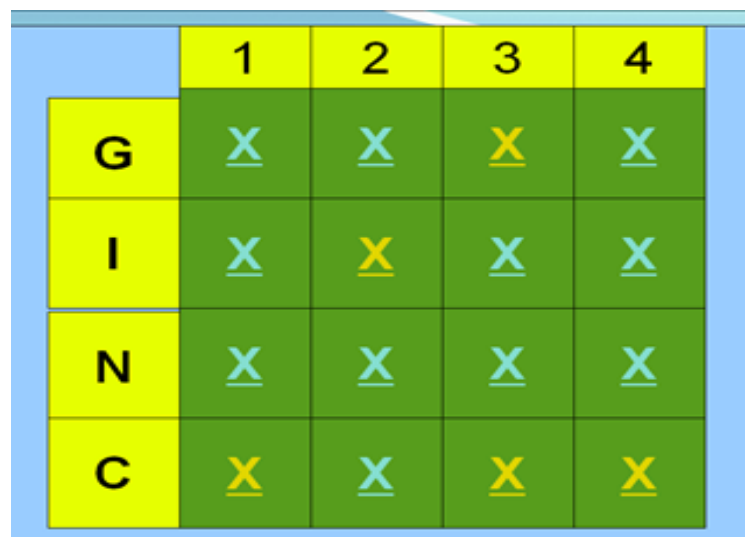

Fonte: Arquivos dos autores, 2021.

Com isso, ao serem abertos todos os quadrados da partida, fizemos a soma das pontuações adquiridas pelas duas equipes, ganhando a equipe que teve uma maior pontuação. Destarte, durante toda a semana, houve interação através do grupo do WhatsApp para orientá-los nas construções assíncronas, além de tentamos tirar as dúvidas que surgissem durante o processo de vivência da oficina, referente as atividade propostas para a Gincana.

O olhar matemático: socialização das fotografias e paródias 
Neste sexto encontro planejamos as apresentações de duas atividades solicitadas no quarto encontro: a socialização das imagens registradas de suas vivências cotidianas e a paródia construída por eles, que abordassem algum conteúdo matemático.

Imagem 02 e 03 - Recorte do Slide "O olhar Matemático: fotografando o nosso redor"

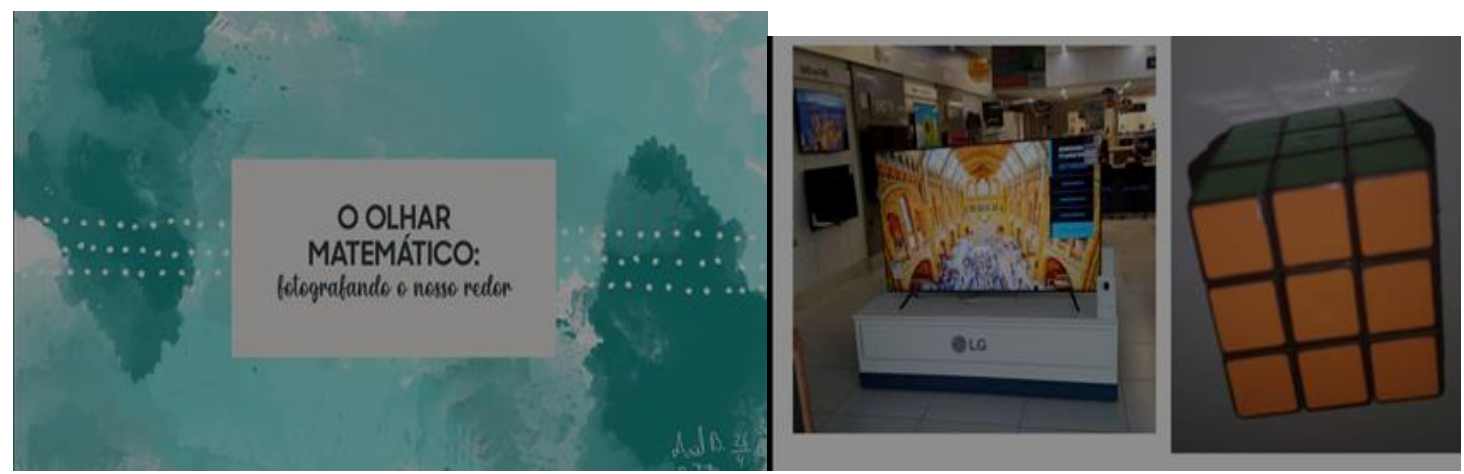

Fonte: Arquivos dos autores, 2021.

Nesse sentido, apresentamos os slides com as imagens fotografadas pelas duas equipes. Para não separá-los nas discussões, optamos em colocar as imagens juntas; pois, eles saberiam ao visualizar os slides no decorrer do encontro quais eram as imagens que eles compartilharam conosco no grupo do WhatsApp. Vale destacar que essas imagens e uma síntese das discussões construídas foram postadas no perfil do Instagram das equipes. Sendo assim, deixamos livres para eles descreverem oralmente a matemática presente em cada imagem, valorizando as suas percepções e, quando necessário, questionando-os para ajudar na ampliação do olhar quando a imagem apresentada. Por fim, as paródias foram apresentadas. Uma das apresentações, por exemplo, foi construída a partir da música do filme Rei Leão, Hakuna Matata. Essa paródia foi articulada com conteúdo de Teorema de Pitágoras.

\section{Introdução ao Geogebra}

No sétimo encontro pensamos em apresentar aos estudantes um software de Geometria dinâmica: o GeoGebra. A princípio, fizemos uma breve descrição, explicitando as funções de cada ferramenta, mostrando um pouco da sua interface. Em seguida, apresentamos algumas de suas ferramentas, como a "Ponto", "Segmento", "Polígono" e "Polígono Regular", além de mostrarmos algumas das opções de personalização como mudar a cor e renomear alguns dos elementos do Geogebra; depois, explicamos sobre a ferramenta "Controle Deslizantes". Para finalizar, 
permitimos que os estudantes explorassem e socializassem as construções, tirando algumas dúvidas que surgiram.

\section{Áreas de figuras planas}

O oitavo encontro começou com o trabalho, por nós estagiários, dos conceitos voltados às Figuras Planas. Inicialmente, tentamos aproximar os conceitos explorados com a realidade dos alunos, por exemplo, explorando sobre a densidade de pixels em uma imagem, o tamanho de uma tela e o cálculo da área de algum cômodo para colocar o piso. Durante esse momento, também, pedimos a eles para citar alguns exemplos de aplicações ou de situações onde eles precisaram mobilizar esses conceitos.

Imagem 04 e 05 - Recorte do Slide "Áreas de figuras planas”

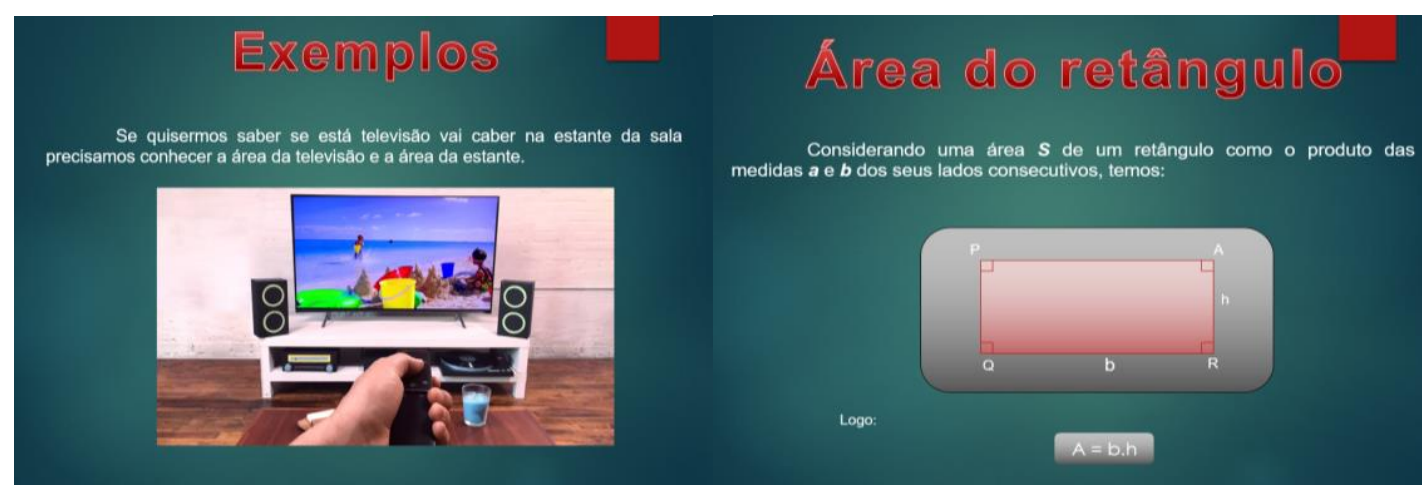

Fonte: Arquivos dos autores, 2021.

Em seguida, no intuito de resgatar alguns dos conhecimentos de Geometria dos alunos, fizemos uma breve explicação, com o auxílio do slide, sobre alguns dos elementos dos polígonos, como lado, vértice e diagonal. Logo após, mostramos imagens de algumas figuras planas e do processo de como encontrar a sua área.

O terceiro momento ficou reservado para a utilização do GeoGebra pelos estudantes, onde fosse possível realizar a construção de algumas figuras planas. Foram retomadas algumas das funções do software. Por fim, pedimos para que os mesmo, de forma assíncrona, realizassem a construção dessas figuras, e a gravação de um vídeo curto mostrando a animação do "controle deslizante".

A vivência com o jogo Batalha Naval com Lógica 
O nono encontro iniciou com um momento para explicar brevemente as regras do Jogo Batalha Naval convencional; seguido da explanação da "batalha naval com lógica", com a única diferença sendo as dicas que seriam mostradas no canto da tela. Essas dicas dão vantagens no jogo para aqueles que conseguirem compreender os conceitos matemáticos descritos nas mesmas (Multiplicação, localização, noções de espaço, paralelismo e perpendicularismo).

Imagem 06 - Recorte da Batalha Naval com Lógica

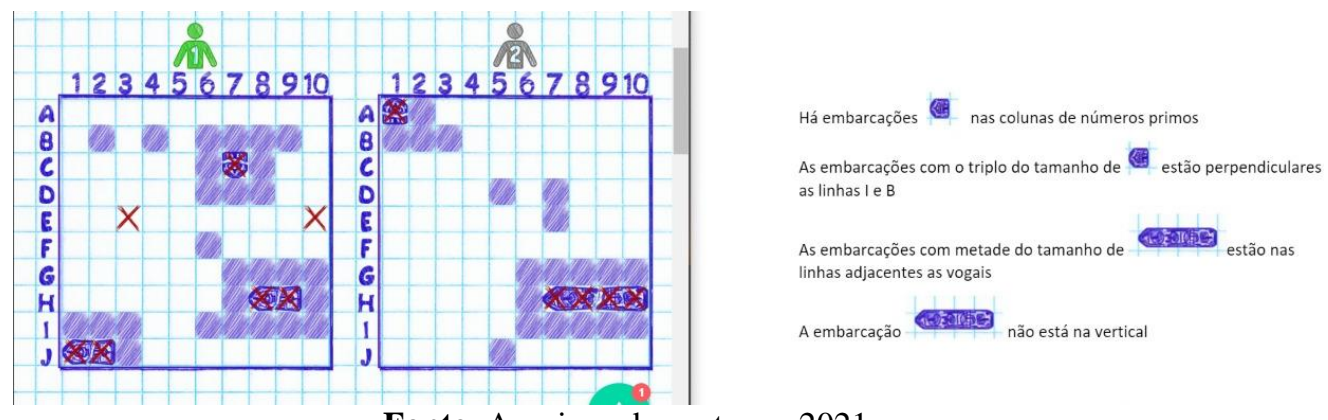

Fonte: Arquivos dos autores, 2021.

Ao iniciarmos o jogo, percebemos certa dificuldade no entendimento das dicas, que foi algo contornado pelos alunos durante o jogo. Como evidenciaram Silva, Souza e Cruz (2020), é importante permitir essa vivência inicial para que os participantes se apropriem das regras durante o movimento de jogar. Durante o encontro percebemos um grande senso de competitividade, algo que em determinados momentos podiam prejudicar os movimentos de socialização e aprendizagem matemática. Ficamos atentos, depois dessa percepção, para tentar estimular o trabalho em equipe.

\section{Aprimorando os conhecimentos de raízes e potenciação}

Para esse décimo encontro objetivou-se revisar o conteúdo de radiciação e de potenciação, visto que, percebemos durante as observações as aulas, algumas dificuldades quanto a esses conteúdos. Considerando isso, fizemos uma contextualização do termo "raiz quadrada", fazendo uma analogia do seu sentido matemático com o seu sentido literal, a partir de três imagens, uma delas contendo uma raiz com o formato semelhante a um quadrado, a segunda contendo a representação geométrica de uma raiz quadrada e a terceira com representação geométrica de uma raiz cúbica. Em seguida, exploramos alguns dos elementos das raízes. Logo após, 
levantamos algumas questões sobre as raízes quadradas e cúbicas. Esse momento foi de grande importância, pois nos permitiu perceber algumas das dificuldades dos alunos em visualizar figuras tridimensionais e seus elementos.

Em seguida, iniciamos a explicação do conteúdo de Potenciação, mostrando a nomenclatura e os seus componentes, mostramos também as propriedades dessa operação através do vídeo "Expoente negativo. Porque inverter a base?" disponível no YouTube. Por fim, finalizamos tirando as dúvidas que surgiram durante o encontro.

\section{Potenciação e Radiciação com auxílio do aplicativo Kahoot}

Esse foi o penúltimo encontro da gincana e neste dia aconteceu o encontro coletivo com as duas turmas. Foi um encontro decisivo, pois foi o último dia de disputa entre as duas equipes. Explicamos como iria funcionar a oficina do dia, com a utilização do aplicativo kahoot. A primeira questão foi aberta e demos o tempo para que respondessem, porém quando iríamos para a segunda questão houve um problema técnico com relação à internet impossibilitando a abertura da tela do aplicativo em tempo real, conforme os estudantes iam respondendo. Com isso, fomos para o "plano b" pedindo aos alunos que quando terminassem o jogo tirassem um print da tela do celular ou uma foto da tela, nos enviando no grupo do WhatsApp. Depois disso, exploramos as estratégias usadas para a resolução das questões.

\section{Socializando as aprendizagens}

Iniciamos o nosso último encontro realizando a socialização e recordando as atividades vivenciadas durante os encontros, no qual tivemos inúmeras atividades que foram pontuadas e somadas em um ranking; e também as revisões dos conteúdos utilizando metodologias alternativas e ativas. Além disso, apresentamos os perfis das equipes no Instagram, que serviu para que os participantes publicizagem todas as atividades construídas nesse período.

Com isso, saudamos a todos e agradecendo bastante a participação durante todo esse processo desenvolvido na Escola. Assim, dando continuidade, apresentamos um vídeo motivador para já darmos início a algumas reflexões sobre a nossa existência, caminhada e realizações. E, assim, começamos a recordar as atividades desenvolvidas nas últimas semanas. Daí, resumimos um pouco do que aconteceu nessa oficina, sempre 
questionando-os sobre: Quais atividades que mais gostaram? Qual era mais recorrente nas memórias deles? Se conseguiram aprender através das atividades propostas? Dessa forma, recebendo respostas positivas enquanto a nossa proposta de oficina.

Nesse sentido, relembramos alguns momentos marcantes que vivenciamos, além disso, pedimos aos estudantes que citassem as atividades significativas para eles; sendo assim, apontaram a Construção da Paródia Matemática, da Batalha Naval Geométrica, do Kahoot e as questões de potenciação e radiação nessa atividade; do Plano Cartesiano Interativo, além de falarem da nossa metodologia adotada com a utilização de Slides, Videoaulas do YouTube, Geogebra, Cordel, Músicas e entre outras.

Dialogamos durante boa parte do encontro, foi uma conversa leve, sobre a Matemática e suas interfaces em nossas vidas, e assim, podemos perceber que os estudantes tinham alcançado os objetivos traçados por nós estagiários durante o planejamento dessa Gincana Matemática; pois os participantes falavam abertamente tudo que recordavam e onde percebiam a Matemática, dessa forma, ficamos bastante satisfeitos. Feito o cálculo das pontuações adquiridas pelas equipes, consagramos a equipe campeã.

\section{CONSIDERAÇÕES FINAIS}

A pandemia vivida por todos, nesse momento, nos trouxe desafios, mudanças no nosso modo de pensar e de agir. A formação docente, por exemplo, precisou ser (re)pensada para atender as diversas demandas apresentadas pela contemporaneidade; nessa direçao, o Estágio Curricular Supervisionado, precisou ser repensando para acontecer na virtualidade, o que nos fez refletir sobre práticas que antes não eram pensadas como, por exemplo, a realização de um estágio exclusivamente no virtual.

O ECS se torna crucial em um curso de licenciatura, pois é nesse momento em que assumimos um papel crítico e reflexivo da docência, e vivenciamos o que ser um profissional da educação. Por ser um estágio que se divide em momentos em que nos permite observar, analisar e refletir; e logo em seguida, após as nossas analyses, o planejar de uma proposta de intervenção priorizando a ressignificação da imagem que muitos tem da Matemática, assegurando melhores aprendizagens.

Nessa direção, portanto, reconhecendo essa importância de construção de relações e diálogo entre a universidade e as escolas da Educação Básica, entendo do quão contribui para o movimento de constituição da identidade docente, destacamos a 
necessidade de promoção de outros espaços, desde o início do curso, onde essa relação com o "chão da sala de aula" aconteça, sejam espaços como o PIBID, outros componentes curriculares que pensem essa iniciação à docência, ou nos estágios acontecerem em outros momentos, não apenas no final do curso.

A gincana, por meio das metodologias ativas e alternativas, nos permitiu aproximação a realidade, trazendo-nos a articulação da teoria e prática, e possibilitando experiências importantes para a constituição da identidade docente. Junto a isso, a vivência da gamificação nos mostrou a necessidade de reestruturação para que o caráter exacerbado da disputa não estrangulasse o caráter lúdico.

\section{REFERÊNCIAS}

ALVES, Lynn Rosalina Gama; MINHO, Marcelle Rose da Silva; DINIZ, Marcelo Vera Cruz. Gamificação: diálogos com a educação. 2014.

BAHIA. Documento Curricular Referencial da Bahia para Educação Infantil e Ensino Fundamental. Secretaria da Educação. Superintendência de Políticas para Educação Básica. União Nacional dos Dirigentes Municipais da Bahia. União Nacional dos Dirigentes Municipais de Educação. Salvador: Secretaria da Educação, 2019.

BAHIA. Resolução 2016/2019. Regulamento Geral de Estágio da Universidade do Estado da Bahia. Salvador: Universidade do Estado da Bahia, 2019.

BARBOSA, M. C. S; ALVES, V. S. Metodologias Alternativas no Ensino de Matemática: um estudo nas escolas de Tempo Integral. Anais do Colóquio Internacional" Educação e Contemporaneidade", v. 13, n. 20, p. e13192039-e13192039, 2019. Disponível em:

http://anais.educonse.com.br/2019/metodologias_alternativas_no_ensino_de_matematic a_um_estudo_nas_e.pdf. Acesso em: 25 abr 2021.

COELHO, N; ORZECHOWSKI, S. T. A função social da escola pública e suas interfaces. In: CONGRESSO NACIONAL DE EDUCAÇÃO-EDUCARE. 2011. Disponível em: https://educere.bruc.com.br/cd2011/pdf/6443_3792.pdf. Acesso em: 18 jun 2021.

CORREIA, V. C. P; SILVA, A. J. N. O Estágio e a Formação do Professor de Matemática. REVISTA BRASILEIRA DE EDUCAÇÃO BÁSICA, v. 5, p. 1-8, 2020.

D’AMBRÓSIO, B. S. Como ensinar matemática hoje. Temas e Debates. SBEM. Ano II. n, v. 2, p. 15-19, 1989.

FREITAS, B. M; DA SILVA COSTA, E. A; LIMA, M. S. L. O estágio curricular supervisionado e construção da profissionalidade docente. Revista Expressão Católica, v. 6, n. 1, p. 36-42, 2018. 
GIOVANNI, J. R. Aprendendo matemática. São Paulo: FTD, 1999.

IEZZI, G; DOLCE, O; DEGENSZAJN, D; PÉRIGO, R; ALMEIDA, N.

MATEMÁTICA: Ciência e Aplicações. $2^{\mathrm{a}}$ serie: ensino médio, matemática. 2 ed. São Paulo: Atual, 2004.

LUCKESI, C. Ludicidade e formação do educador. Revista Entreideias: educação, cultura e sociedade, v. 3, n. 2, 2014.

NAME, M. A. Vencendo com a Matemática. São Paulo: Editora do Brasil, 2005.

MORÁN, J. Mudando a educação com metodologias ativas. Coleção mídias contemporâneas. Convergências midiáticas, educação e cidadania: aproximações jovens, v. 2, n. 1, p. 15-33, 2015. Disponível em:

https://edisciplinas.usp.br/pluginfile.php/4941832/mod_resource/content/1/ArtigoMoran.pdf. Acesso em: 21 abr. 2021.

MUNIZ, C. A. Educação Lúdica da matemática, Educação Matemática Lúdica. In: Silva, A. J. N; Teixeira, H. S (Org.). Ludicidade, formação de professores e educação matemática em diálogo - $1^{\circ}$ ed. - Curitiba, Appris, 2016.

PAVIANI, N. M. S. Oficinas pedagógicas: relato de uma experiência. CONJECTURA: filosofia e educação, v. 14, n. 2, 2009. Disponível em: http://ucs.br/etc/revistas/index.php/conjectura/article/view/16. Acesso em: 18 jun. 2021.

PIMENTA, S. G. Formação de professores: identidade e saberes da docência. In: PIMENTA, Selma Garrido. (Org.). Saberes pedagógicos e atividade docente. São Paulo: Cortez Editora, 1999. p. 15-34.

PIMENTA, S. G; LIMA, M. S. L. Estágio e docência. São Paulo: Cortez, 2004.

PIMENTA, S. G; O estágio na formação de professores: unidade, teoria e prática? 11. ed. São Paulo: Cortez, 2012.

SARAIVA, K; TRAVERSINI, C. S; LOCKMANN, K. A educação emtempos de COVID-19: ensino remoto e exaustão docente. Práxis educativa. Ponta Grossa, PR. Vol. 15 (2020), e2016289, p. 1-24, 2020.

SILVA, A. J. N. SOUZA, I. S; SOUZA, S. S; ALMEIDA; J. S. O professor de Matemática e o Ato de Planejar: Há unicidade entre dimensão política e dimensão pedagógica. SILVA, A. J. N; SOUSA, I. S. A Formação do Professor de Matemática em Questão: Reflexões para um Ensino com Significado, Jundiaí: Paco Editorial, 2014.

SILVA, A. J. N. Querido diário... o que revelam as narrativas sobre ludicidade, formação e futura prática do professor que ensina (rá) matemática nos anos iniciais. Tese de Doutorado. Universidade Federal de São Carlos, UFSCar, 2018. 
SILVA, A. J. N. da; SOUZA, I. S. de; CRUZ, I. S. O ensino de Matemática nos Anos Finais e a ludicidade: o que pensam professora e alunos?. Educação Matemática Debate, v. 4, n. 10, p. e202018-e202018, 2020.

SILVA, A. J. N. da. Professores De Matemática Em Início De Carreira E Os Desafios (Im)Postos Pelo Contexto Pandêmico: Um Estudo De Caso Com Professores Do Semiárido Baiano: doi.org/10.29327/217514.7.1-5. Revista IberoAmericana de Humanidades, Ciências e Educação, [S. 1.], v. 7, n. 1, p. 17, 2021 a. Disponível em: http://periodicorease.pro.br/rease/article/view/430. Acesso em: 21 abr. 2021.

SILVA, A. J. N. da. "Prática" e "Estágio Supervisionado" na formação de professores: o que revela um curso de Licenciatura em Matemática da UNEB?. Revista de Educação Matemática, v. 17, p. e20034, 2020.

SOUZA, E. M. DE F., FERREIRA, L. G. Ensino remoto emergencial e o estágio supervisionado nos cursos de licenciatura no cenário da Pandemia COVID 19. Revista Tempos E Espaços Em Educação, 13(32), 1-19. 2020. Disponível em: https://doi.org/10.20952/revtee.v13i32.14290. Acesso em: 20 jun. 2021.

SUZART, L. A; SILVA, A. J. N. O Estágio Supervisionado e o constituir-se professor de Matemática: “ser ou não ser professor”? EDUCAÇÃO BÁSICA REVISTA, v. 6, p. 131-141, 2020. 